JGG 2022:70:40-49

doi: $10.36150 / 2499-6564-N 398$

\section{Verification of the causes of and countermeasures for falls using fall assessment score sheets in a municipal hospital}

\author{
Mana Shibata', Akihiro Isoda², Tomoko Ogasawara ${ }^{3}$, Kaneko Satio ${ }^{4}$, \\ Yutaka Inoue ${ }^{1}$ \\ ${ }^{1}$ Laboratory of Nutri-Pharmacotherapeutics Management, Faculty of Pharmacy and \\ Pharmaceutical Sciences, Josai University, Sakado, Saitama, Japan; ${ }^{2}$ Department of Pharmacy, \\ Chichibu Municipal Hospital, Chichibu, Saitama, Japan; ${ }^{3}$ Department of Nursing, Chichibu \\ Municipal Hospital, Chichibu, Saitama, Japan; ${ }^{4}$ Department of Rehabilitation, Chichibu Municipal \\ Hospital, Chichibu, Saitama, Japan
}

Aim. This study aimed to examine the causes and countermeasures concerning falls through evaluating patient falls assessment score sheets at admission and retrospectively examining medication use and biochemical evaluation results.

Methods. The medical records of patients hospitalized for 11 months from April 2018 to March 2019 were reviewed anonymously on the basis of medical safety and the safety of medical supplies, and the number of falls was determined. Moreover, the cause and number of falls were reviewed retrospectively based on patient falls assessment score sheets. On assessment of the causes of falls during hospitalization, activity restrictions were noted and physical restraints had been implemented to assist with activities of daily living due to suspected frailty syndrome. Results. As a result of the evaluation of the fall assessment score sheet, 256 patients (90.5\%) were aged 65 years or older, and most of the hospitalized patients were elderly. Regarding the history of falls, the number of males aged 65 years or older (136 patients) with a history of falls was approximately 2.7 times that of those without a history (99 patients), and the number of female patients (120 patients) with a history of falls was twice that of those without a history of falls (80 patients). As fall assessment items, it was confirmed that needing assistance for elimination, patient use of accessories, IVs, gastric tubes, drains, and use of wheelchair toilets contributed to the cause of falls. Biochemical evaluations indicated that patients categorized as underweight, based on their body mass index, had lower total protein, albumin, and hemoglobin levels than obese patients.

Conclusions. To reduce the occurrence of falls, a patient's nutritional status and muscle mass should be considered using a falls assessment score sheet at admission. Furthermore, falls may be prevented through evaluating a patient's nutritional status from a biochemical perspective.

Copyright by Società Italiana

di Gerontologia e Geriatria (SIGG)

(c) (1) (2) $\odot$

OPEN ACCESS

This is an open access article distributed in accordance with the CC-BY-NC-ND (Creative Commons Attribution-NonCommercial-NoDerivatives 4.0 International) license. The article can be used by giving appropriate credit and mentioning the license, but only for non-commercial purposes and only in the original version. For further information: https://creativecommons.org/licenses/by-nc-nd/4.0/deed.en
Key words: activity suppression and patients, assessment score, hospitalization falls, nutritional 


\section{INTRODUCTION}

Japan currently has the highest percentage of older adults aged $>65$ years worldwide and faces challenges concerning social security costs in terms of care for older adults and health insurance because of high healthy life expectancy ${ }^{1,2}$. In 2025, many of those belonging to the baby boomer generation (that is, those born between 1946 and 1964) will be aged > 75 years, and an increase in chronic illness and cognitive dysfunction is predicted. Therefore, healthcare workers are likely to become increasingly burdened and access to medical treatment may become potentially more limited, with more challenging implications for managing supply and demand requirements. Thus, it is important to extend the healthy life expectancy of older adults through securing the most suitable medical treatment ${ }^{3}$ to improve the outcomes following cognitive dysfunction, joint diseases, fall prevention and bone fractures, other geriatric syndromes ${ }^{4-6}$. Saitama Prefecture, Japan, is aiming to promote a "prosperous and environfment friendly city in Chichibu where the Japanese government is in harmonious partnership with its citizens" 7 . "The city is known for its high number of older adult citizens who live long and peaceful lives (a city where cooperation and warmth are felt)". Based on this understanding, the "Healthy Chichibu 21 ( $2^{\text {nd }}$ plan)" also comprised a "Chichibu Positive Health Plan", which is an older adult citizen welfare program. Citizens aim for "healthy longevity in Chichibu" to live full and healthy lives. The "Healthy Chichibu 21 ( $2^{\text {nd }}$ plan)" has five objectives, namely: (i) to extend healthy life expectancy; (ii) to prevent lifestyle related diseases and serious illnesses; (iii) to improve daily habits in relation to nutrition, eating habits, physical activity and exercise, sleeping, alcohol consumption, cigarette smoking, and oral health; (iv) to maintain and improve functions necessary for an active social life; and (v) to maintain a social environment that supports and protects good health ${ }^{7}$. In Chichibu city, it has been predicted that as the overall population decreases, the number of older adults will increase and that the aging rate will exceed $35 \%$ by $2025^{1}$. A number of falls have occurred at the one of municipal hospital involving older adults, with causes related to previously reported factors such as frailty, recognition dysfunction prevention ${ }^{8}$. Falls are generally categorised into 'internal' and 'external' factors. In this process, falls which are considered to be characteristic of municipal hospital can be categorized as follows. The hospitalization process, the dementia caused by the disease, the frequency of urination at night, and medications: polypharmacy (multiple drug prescription with adverse events) ${ }^{9}$ are all factors. The reason for focusing on falls is that they are caused by the patient's spontaneous actions and the impact on the patient can be disabling, especially when fractures occur, leading to prolonged hospitalisation, muscle weakness and repeated falls. In the elderly, this can lead to death. And even if patients expect to return to their pre-hospital life, they often do not fully recover, causing changes in mental health and social aspects such as the implications for work and family. On the economic side, the patient may have to pay for extra treatment. The use of multiple medications is commonly referred to as polypharmacy. It is common for the elderly who suffer from multiple diseases to use more than one drug to treat each disease. Polypharmacy is associated with adverse outcomes including mortality, falls, adverse drug reactions, increased length of stay in hospital and readmission to hospital soon after discharge ${ }^{10}$. Polypharmacy and medications that increase the risk of falls are prevalent in patients discharged from orthopedic surgery after fracture of the hip ${ }^{11,12}$. At present, nurses at municipal hospital evaluate the occurrence of falls using an assessment score sheet (Tab. I); however, determining a falls history, in terms of the number of previous falls, can be challenging. Since polypharmacy has been reported to be associated with falls in older adults, pharmacists should be involved in falls assessments to optimize patient medication ${ }^{13}$, as this may help reduce the number of fall related incidents due to medication. The medical records of patients hospitalized were reviewed anonymously on the basis of medical safety and the safety of medical supplies, and the number of falls was determined. Moreover, the cause and number of falls were reviewed retrospectively based on patient falls assessment score sheets. Therefore, in this report, we hope to discover new elements by summarizing and analyzing cases of falls in municipal hospitals, which will help to further build medical safety.

\section{MATERIALS AND METHODS}

\section{SUBJECTS}

The medical records of patients hospitalized for 11 months from April 2018 to March 2019 were reviewed anonymously on the basis of medical safety and the safety of medical supplies, and the number of falls was determined. Moreover, the cause and number of falls were reviewed retrospectively based on patient falls assessment score sheets. In total, 283 patients with a history of falls (men, $n=147$; women, $n=136$ ) who had been admitted to Chichibu Municipal Hospital. Patient information, including sex, age, height, weight, total protein, albumin, and hemoglobin levels; the type and number of medications administered, and, data concerning patient falls assessment score sheets, 
were obtained from alphabetically organized electronic patient records. Data analysis was performed anonymously at Josai University, Sakado Campus. Permission to undertake this research was obtained from the Medical Science Course Study Ethics Review Committee at Josai University. All study procedures were conducted in compliance with the principles of the Declaration of Helsinki and its later amendments, as well as with the nationally applicable guidelines for research on human patients.

\section{PATIENT FALLS ASSESSMENT SCORE SHEET}

A patient falls assessment score sheet was used to evaluate a patient's status and hazardous factors to determine the risk of falling. This assessment comprises 11 items (A-K), and more than one answer is possible for each (Tab. I). A score was set for every observation, and the sum of the 11 items was indexed into a comprehensive falls assessment and classified as follows: dangerous degree I (1-9 points), dangerous degree || (10-19 points), and dangerous degree III (> 20 points). Changes in patient status during hospitalization were also considered; thus, patient risk assessments concerning falls were undertaken more than once during hospitalization. To investigate factors causing falls in inpatients in this study, a chart was used to record all checks and items derived from the assessment score sheet concerning patient falls. The influence of polypharmacy was also considered, as was patient history of medication and the number of medications administered.

\section{CLINICAL BIOCHEMICAL EVALUATION}

Sex, age, height, weight, and total protein, albumin, and hemoglobin levels were collected from the patients' electronic medical records at Chichibu Municipal Hospital and the respective distribution was estimated using a box-and-whisker plot. Body mass index (BMI) was classified as follows: low, $<18.5 \mathrm{~kg} / \mathrm{m}^{2}$; healthy, $18.5 \mathrm{~kg} / \mathrm{m}^{2}$ to $<25 \mathrm{~kg} / \mathrm{m}^{2}$, and overweight, $\geq 25 \mathrm{~kg} / \mathrm{m}^{2}$, according to the Japanese overweight academic meeting. The distribution of patients' total protein, albumin, and hemoglobin levels, which were classified according to BMI, was estimated using a box-and-whisker plot.

\section{EVALUATION OF MEDICATION}

The number and type of medications taken were collected and anonymized from each patient's electronic medical record at Chichibu Municipal Hospital. Data regarding the names of medication a patient had taken prior to a fall, the names of any discontinued medications, and their current medication were used.

\section{RESULTS AND DISCUSSION}

\section{PreVious history OF FalLS}

An algorithm was used to analyze patients' age, sex, and history of falls at the Chichibu Municipal Hospital (S.I 1 and 2). In our study, 256 (90.5\%) inpatients were $>65$ years old. Females $(n=120)$ were twice as likely to have a past history of falls ( $n=80$ patients) and were approximately 2.7 times more likely to fall $(n=40$ patients) than males who had no previous medical history ( $n=37$ patients), males aged $>65$ years $(n=99$ patients), and males with a past medical history ( $n=136$ patients). A history of falls was recorded in 2 patients aged $>10$ years or less than 9 years and in 25 patients aged $<64$ years. Therefore, we considered that falls were likely to occur in patients with a past history of falls.

\section{Patient falls assessment score sheet Results}

Figure 1 lists the patient falls assessment score sheet values. Patient age (A) and anamnesis (B) are detailed in Section 3.1. Cognition, knowledge, and memory (53.4\%, 151 patients) (C) were significantly affected by recognition capacity (Fig. 2A). An older adult has approximately $90 \%$, and Chichibu Municipal Hospital is expected to have many patients with a decline in recognition capacity. Medications used (D) were as follows: diuretics to lower blood pressure (84 patients; $46.6 \%$ ), laxatives (64 patients; $22.6 \%$ ), other drugs

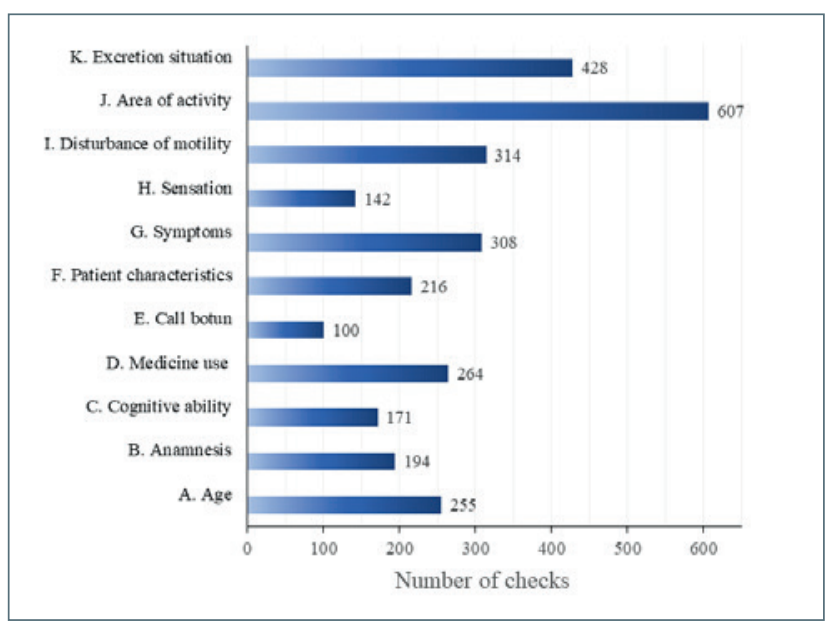

Figure 1. Results of the patient falls assessment score sheet (multiple answers possible). 
Table I. Assessment score sheet for patient falling and tumble of Chichibu municipal hospital

\begin{tabular}{|c|c|c|}
\hline Assessment score & Check List & Score \\
\hline \multirow[t]{4}{*}{ Situation of evaluation } & Hospitalization first day & \multirow[t]{4}{*}{-} \\
\hline & Hospitalized two days after & \\
\hline & At the start of rehabilitation, ADL/symptom change & \\
\hline & Fall event occurrence, 4 weeks after chronic patients & \\
\hline A. Age & $\geq 65$ years old, 9 years old and under & Yes: 2 \\
\hline B. Anamnesis & Fall history & Yes: 2 \\
\hline \multirow[t]{4}{*}{ C. Cognitive ability } & Dementia symptoms & Yes: 4 (yes, if even one is true) \\
\hline & Disturbing behavior & \\
\hline & Poor judgment, comprehension, and memory & \\
\hline & Disorientation/turbidity & \\
\hline \multirow{5}{*}{$\begin{array}{l}\text { D. Medicine use (history of } \\
\text { prescription) }\end{array}$} & Sleep-inducing drugs/tranquilizers & Yes: 2, for sleep-inducing drugs and tranquilizers. \\
\hline & Sedative (analgesic) drug & \multirow{4}{*}{$\begin{array}{l}\text { Yes: 1, furthermore, except for sleep-inducing drugs and } \\
\text { tranquilizers, even one Yes equates to } 1 \text { point }\end{array}$} \\
\hline & Medical narcotics & \\
\hline & Laxative & \\
\hline & Antihypertensive drug & \\
\hline \multirow[t]{2}{*}{ E. Call button } & Acts without using the nurse call button & \multirow[t]{2}{*}{ Yes: 4 (yes, if even one is true) } \\
\hline & Cannot recognize/use the nurse call button & \\
\hline \multirow[t]{3}{*}{ F. Patient characteristics } & Conspicuous behavior & Yes: 2 \\
\hline & Try to do everything by myself & \multirow{2}{*}{$\begin{array}{l}\text { Yes: 1, furthermore, except for equipped with } \\
\text { accessories, even one Yes is } 1 \text { point. }\end{array}$} \\
\hline & $\begin{array}{l}\text { Equipped with accessories (IVs, feeding tubes, drains, } \\
\text { etc.) }\end{array}$ & \\
\hline \multirow[t]{6}{*}{ G. Symptoms } & Fever ( $38^{\circ}$ or higher) & Yes: 3 , fever ( $38^{\circ}$ or higher), \\
\hline & Anemia tendency & Anemia tendency \\
\hline & Dizziness on standing up & Lightheadedness (yes, if even one is true) \\
\hline & Within 3 days after surgery & Yes: 2 , Within 3 days after surgery \\
\hline & Rehabilitation & \multirow{2}{*}{$\begin{array}{l}\text { Yes: } 1 \text {, rehabilitation, decreased symptoms and ADL (yes, } \\
\text { if either one is true) }\end{array}$} \\
\hline & Decreased symptoms and ADL & \\
\hline \multirow[t]{2}{*}{ H. Sensation } & Visual field impairment, hearing impairment & Yes: 1 (yes, if even one is true) \\
\hline & Balance disorders & Yes: 3, for weak legs and weak muscles. \\
\hline \multirow[t]{4}{*}{ I. Disturbance of mobility } & Weak legs and weak muscles & Yes: 1, furthermore, except for \\
\hline & Numbness & \\
\hline & Fatigue & \multirow[t]{2}{*}{ Weak legs and weak muscles, even one yes is 1 point. } \\
\hline & Bone and joint abnormalities (restraint, deformity) & \\
\hline \multirow[t]{6}{*}{ J. Area of activity } & Staggering & Yes: 3, staggering \\
\hline & Wheelchair use & Yes: 2, wheelchair use, can move freely respectively. \\
\hline & & Yes: 1, need assistance when moving or bedridden \\
\hline & Can move freely & \multirow[t]{3}{*}{ (Yes, if either one is true) } \\
\hline & Needs assistance when moving & \\
\hline & Bedridden (limbs can be operated) & \\
\hline \multirow[t]{4}{*}{ K. Excretion situation } & Urinary incontinence, frequent urination & \multirow[t]{2}{*}{ Yes: 3 (yes, if even one is true) } \\
\hline & Distance to the toilet, visits to the toilet at night & \\
\hline & Portable toilet, wheelchair toilet & \multirow[t]{2}{*}{ Yes: 1 (yes, if even one is true) } \\
\hline & Intravesical catheter, needs assistance with toileting & \\
\hline
\end{tabular}

(18 patients; 6.4\%), supportive medicine (47 patients; 16.6\%:), and sleep medications or sedatives (29.7\%, 84 patients; Figure 2B). In total, 68 (24\%) patients used the call button $(E)$, whereas $53(18.7 \%)$ patients did not (Fig. 2C). Patient characteristics (F) were identified in relation to the presence of a $\mathrm{J}$ attachment, intravenous drip, stomach pipe, and drains (128 patients; 43.7\%). Patients who could move freely $(20.8 \%, 61$ patients) and those subject to some active bodily restrictions were predicted to experience more falls than patients with unlimited activities (Figs. 2D \& 2H). Approximately $80 \%$ of the patients had a disturbance in motility, poor 


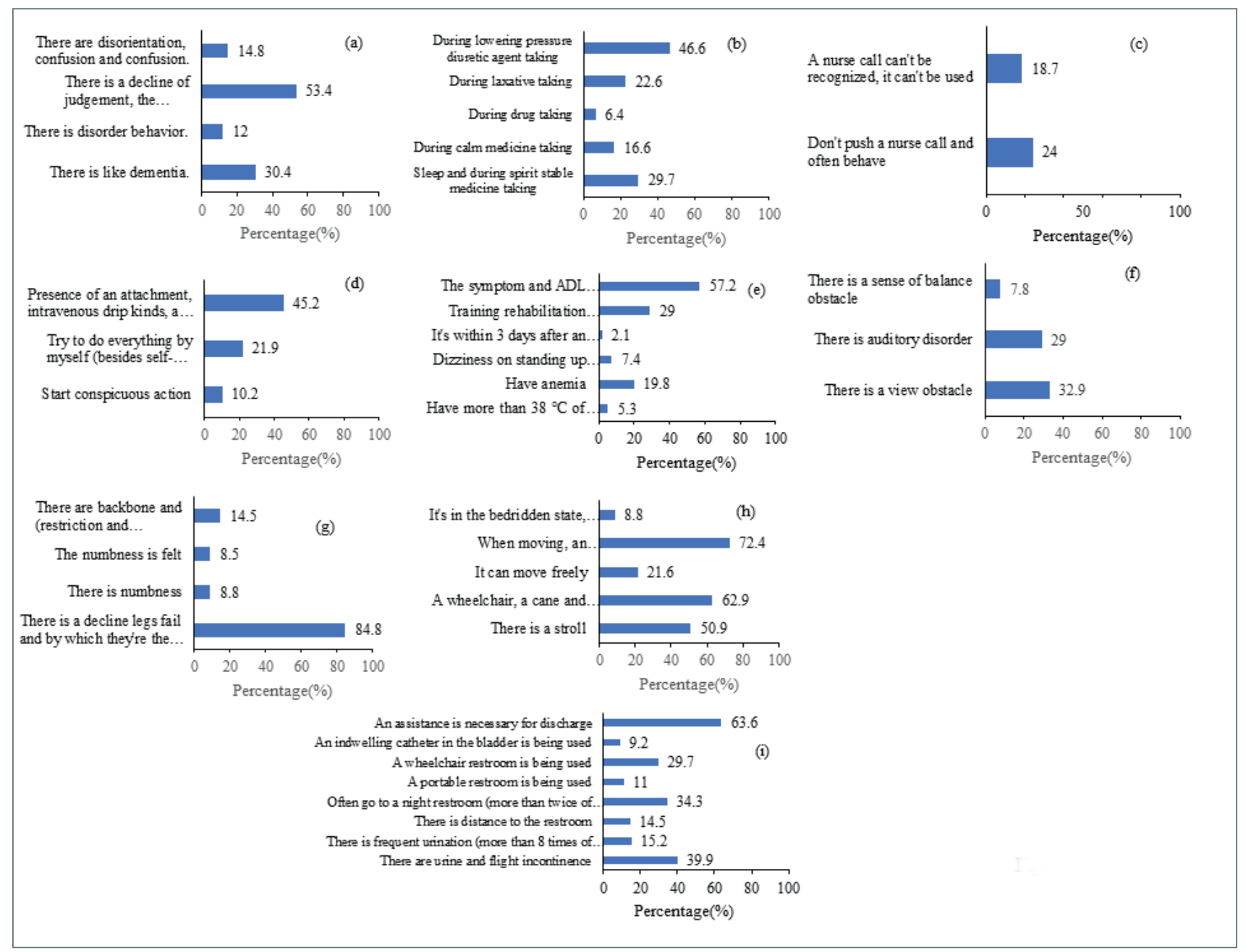

Figure 2. Results of each item in the patient falls assessment score sheet. (a) C, cognition; (b) D, medicine; (c) $E$, call button; (d) F, patient characteristics; (e) G, symptom; (f) H, sensation; (g) I, disturbance of motility; (h) J, area of activity; and (i) K, excretion (multiple answers possible).

leg function, and a decline in muscle strength (240 patients; 81.9\%; Figure 2G). Assistance with toileting (K) was necessary for 180 patients $(63.6 \%)$ for the following: an indwelling catheter (26 patients; $9.2 \%)$, a wheelchair toilet (84 patients; $29.7 \%$ ), a portable toilet (31 patients; $11 \%)$, frequent toilet visits at night (> 2 times at night, 97 patients; 34.3\%), assistance with walking to the toilet (41 patients; $14.5 \%$ ), frequent urination (> 8 times at midday and $>2$ times at night; 43 patients; $15.2 \%)$, and urinary incontinence (113 patients; 39.9\%). Many patients required assistance (Fig. 2l). Older adults aged $>65$ years accounted for approximately $90 \%$ of the patients. Most of the hospitalized patients are older than 65 years old, so physical weakness is expected. With many kinds of frail patients and those with active restrictions in daily life being admitted to municipal hospital, the need for fall prevention care is emphasized at this hospital.

\section{CLASSIFICATION ACCORDING TO POLYPHARMACY FOR EVERY ITEM IN THE PATIENT FALLS ASSESSMENT SCORE SHEET}

The presence of a past history of falls and its relationship to polypharmacy are shown using an algorithm (Fig. 3). One hundred and seventeen (41.3\%) patients had a history of falls and were receiving multiple medications, $78(27.6 \%)$ patients had a history of falls and were not receiving multiple medications, 53 (18.7\%) patients had no history of falls and were receiving multiple medications, and 35 (12.4\%) patients had no history of falls and were not receiving multiple medications. Previous studies have reported that the increased risk of falls in inpatients is related to the adverse effects of $>6$ medications being administered ${ }^{10,11}$. Patients with multiple drug prescriptions have a greater risk of falls than patients not prescribed multiple medications, irrespective of the presence of medical history. Therefore, 


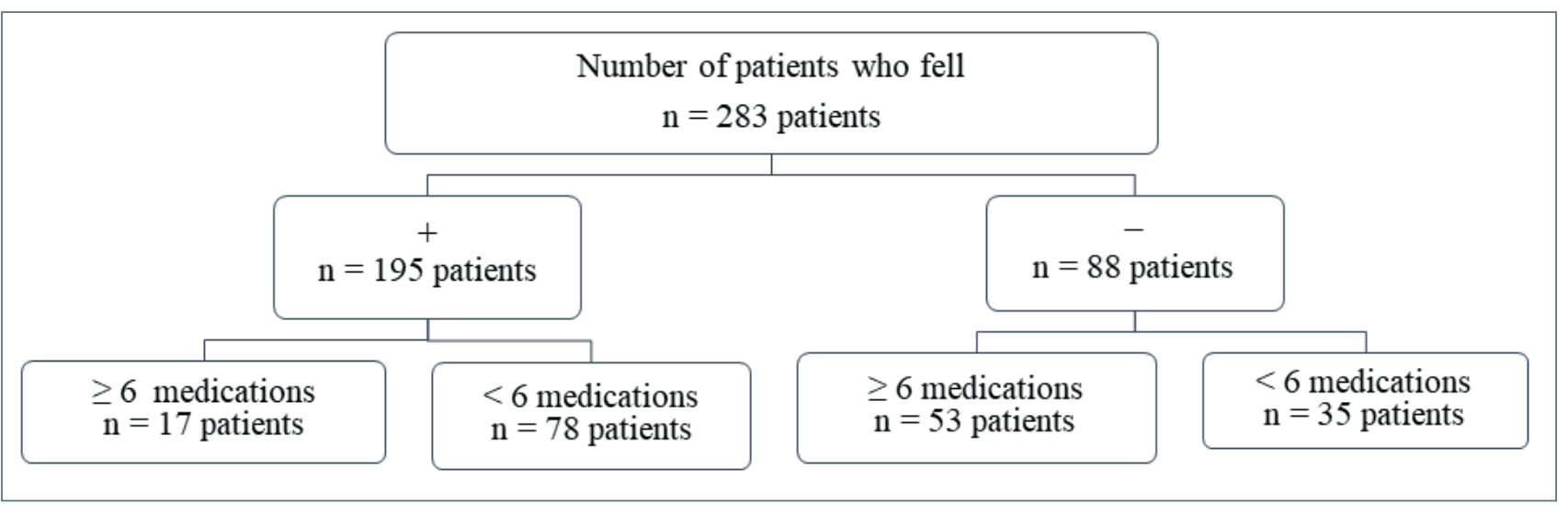

Figure 3. Patient medical and pharmacological history (a positive medical history ['+]'; a negative medical history ['-']).

polypharmacy is considered to be related to the occurrence of a fall. In terms of the relationship between polypharmacy and falls, items on the patient fall assessment score sheet indicated an association between the presence of a history of falls and a history of multiple medications (Fig. 1). Cognition (C) and the need to use the call button (E) were compared and, an association was found between $(C)$ and $(E)$. A patient's ability to use the call button was also found to be a risk factor for falls (Fig. 4A \& 4C). A medical history and the use of $>6$ medications (D) also posed a risk of falls (Fig. 4B). Patient characteristics $(F)$ and symptoms $(G)$ that caused a fall were compared between patients who did and did not have a history of falls, showing that a patient taking $>6$ medications was at risk of falling (Fig. 4D \& 4E). Fall prevention can be facilitated through deter-mining a patient's past history of falls on admission.

\section{Biochemical EVALUATION OF PATIENTS WHO FALL}

$\mathrm{BMI}$ and total protein, albumin, and hemoglobin levels of patients with a history of falls are shown using a box-and-whisker plot (Fig. 5). Normal weight was defined as a BMl of $28 \mathrm{~kg} / \mathrm{m}^{2}$ and being overweight was defined as a BMI of approximately $22 \mathrm{~kg} / \mathrm{m}^{2}$. The median total protein level was approximately $6.0 \mathrm{~g} /$ $\mathrm{dL}$, and approximately $50 \%$ of the patients had a total protein level of $4.5-6.0 \mathrm{~g} / \mathrm{dL}$ (Fig. 5B). When BMl was taken into consideration, the median total protein level was proportional to the BMI value and increased with increase in BMl in some patients (Fig. 5(B)-1). However, $50 \%$ of the inpatients had a standard value $<6.0 \mathrm{~g} / \mathrm{dL}$ irrespective of BMI. The median albumin level was approximately $3.0 \mathrm{~g} / \mathrm{dL}$. The general standard value was $<4.0 \mathrm{~g} / \mathrm{dL}$ (Fig. 5C). When the patients were classified according to BMI, the median was proportional to the $\mathrm{BMI}$ and increased, but all values were below $4.0 \mathrm{~g} / \mathrm{dL}$ in all patients, even those with a BMl $>25 \mathrm{~kg} / \mathrm{m}^{2}$. However, albumin levels generally indicate the nutritional state. One study stated that albumin levels $>3.5 \mathrm{~g} /$ $\mathrm{dL}$ were favorable and that complications were rarely observed clinically when levels were $>3.0 \mathrm{~g} / \mathrm{dL}^{14}$. The median albumin value of underweight patients with a $\mathrm{BMl}<18.5 \mathrm{~kg} / \mathrm{m}^{2}$ and that of normal weight patients with a $\mathrm{BMl}>18.5 \mathrm{~kg} / \mathrm{m}^{2}$ to $<25 \mathrm{~kg} / \mathrm{m}^{2}$ was $<3.0 \mathrm{~g} /$ $\mathrm{dL}$. The risk of falls due to physical dysfunction in the elderly was also estimated, as shown in Figures $2 \mathrm{G}$ and $4 \mathrm{G}$. The median hemoglobin level was approximately $11.0 \mathrm{~g} / \mathrm{dL}$, and approximately $50 \%$ of the study patients had values below the median (Fig. 5D). When the hemoglobin level was sex-segregated and classified according to BMl, both values were proportional to the $\mathrm{BMl}$, and the median value increased. $\mathrm{Hb}$ values for males fell below the standard value $(13.5 \mathrm{~g} / \mathrm{dL})$ in terms of the BMl compared to those in women (Fig. 5(E)-1). In females with a BMl of $>25 \mathrm{~kg} / \mathrm{m}^{2}$, the median hemoglobin level was $12 \mathrm{~g} / \mathrm{dL}$; however, in females with a $\mathrm{BMl}<18.5 \mathrm{~kg} / \mathrm{m}^{2}$ or in those with a $\mathrm{BMI} \geq 18.5 \mathrm{~kg} / \mathrm{m}^{2}$, these values were lower than the standard value compared with those with a BMl of $<25 \mathrm{~kg} / \mathrm{m}^{2}$ (Fig. 5 (F)-1). As a result, there is a possibility of a reduction in total protein, albumin, and hemoglobin levels, and patients classified as underweight had an increased risk of falls. Therefore, given varying total protein and albumin levels because of increased energy demand due to illness, it is necessary for healthcare workers to periodically verify the nutritional status of patients.

\section{EVALUATION OF THE TYPE OF MEDICATION TAKEN}

Medication taken by a patient prior to a fall, discontinued medication, and medication taken immediately before the fall are shown in Table II. Given that polypharmacy was reported, such as taking sleeping tablets or nonbenzodiazepine medication (case A), the possibility of a fall was estimated. Case B involved a patient who was intravenously infused with a mixture of amino acids, glucose, electrolytes, and vitamins. The patient presumably 


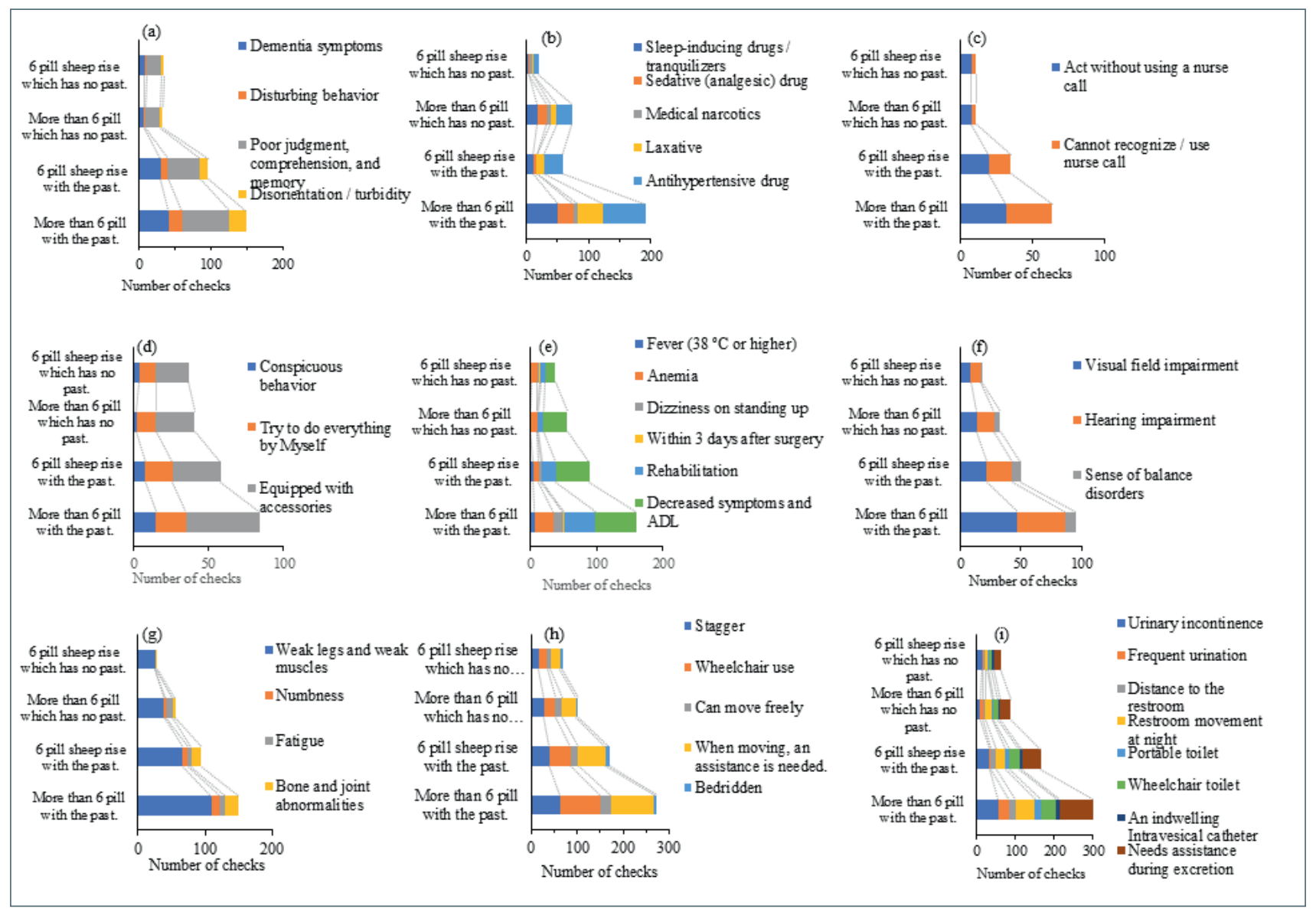

Figure 4. Items in the patient falls assessment score sheet indicate a past history of falls and the presence of multiple medications. (a) C, cognition; (b) D, medicine; (c) E, calling for the nurse, (d) F, patient characteristics; (e) G, symptom; (f) H, sensation; (g) I, disturbance of motility; (h) J, area of activity; and (i) K, excretion.

Table II. Three patients with the highest accident level.

\begin{tabular}{|c|c|c|c|}
\hline Accident level & Additional medication & Discontinued medication & Medication taken prior to the fall \\
\hline & Day 0: apixaban 10 mg & Day 7: quazepam $20 \mathrm{mg}$, daikenchuto & $\begin{array}{l}\text { Day } 11,6 \mathrm{pm} \text { : apixaban } 5 \mathrm{mg} \text {, sertraline } 25 \\
\text { mg, magnesium oxide } 660 \mathrm{mg} \text {, fluphenazine } \\
\text { maleate } 0.5 \mathrm{mg} \text {, mirtazapine } 30 \mathrm{mg}\end{array}$ \\
\hline & $\begin{array}{l}\text { Day 6: magnesium oxide } 660 \mathrm{mg} \text {, then } \\
\text { changed to magnesium oxide } 990 \mathrm{mg}\end{array}$ & $\begin{array}{l}\text { Day 9: fluphenazine maleate } 0.5 \\
\text { mg (twice a day after breakfast and } \\
\text { dinner, then changed to once a day } \\
\text { after dinner) }\end{array}$ & $\begin{array}{l}\text { Day } 11,9 \text { pm: zopiclone } 7.5 \mathrm{mg} \text {, nitrazepam } \\
2 \mathrm{mg}\end{array}$ \\
\hline \multirow[t]{2}{*}{ (a) Lv3b } & $\begin{array}{l}\text { Day 7: tazobactam natrium, } \\
\text { piperacillin natrium IV push, then } \\
\text { changed to levofloxacin } 500 \mathrm{mg}\end{array}$ & & \\
\hline & $\begin{array}{l}\text { Day 0: KCL } 20 \mathrm{mEq} \text {, Amino acid, sugar, } \\
\text { electrolyte and vitamin kit }\end{array}$ & No change & No change \\
\hline (b) Lv3b & $\begin{array}{l}\text { Day 3: Potassium chloride } 1200 \mathrm{mg} \text {, } \\
\text { daikenchuto } 7.5 \mathrm{~g}\end{array}$ & & \\
\hline (c) Lv3b & No change & No change & $\begin{array}{l}\text { Day } 0,6 \text { pm: acetaminophen } 400 \mathrm{mg} \text {, } \\
\text { isosorbide mononitrate } 20 \mathrm{mg} \text {, magnesium } \\
\text { oxide } 330 \mathrm{mg} \text {, Day } 0.9 \text { pm: brotizolam } 0.25 \\
\text { mg }\end{array}$ \\
\hline
\end{tabular}





BMl: body mass index

Figure 5. Biochemistry values for each patient. (a) BMI; (b) total protein; (b-1) total protein classified according to BMl; (c) albumin; (c-1) albumin classified according to BMl; (d) hemoglobin; (d-1) hemoglobin classified according to BMl; (e) sex-segregated male hemoglobin; (e-1) male hemoglobin classified according to BMl; (f) sex-segregated female hemoglobin; and (f-1) female hemoglobin classified according to BMI.

fell as a result of a poor nutritional status and limited physical activity (constraints) due to the intravenous infusion. The risk of falling was high because the patient had taken a sedative immediately prior to the fall. As shown in Table II, no relationship was observed between the type of medication used and the tendency to fall with regard to the time taken, due to inconsistent results in relation to the occurrence of a fall and the addition of a medication or its discontinuation. Some studies concerning reducing the risk of falls have reported digitizing incident reporting systems, installing fall prevention devices, and hourly rounds of nurses to assess fall trends in hospitals ${ }^{15}$. In addition, it has been reported that intervention by a physiotherapist may lead to a reduction in fall events for up to 6 months through providing falls prevention advice, health guidance, and exercise intervention ${ }^{16}$. According to the World Health Organization, multidisciplinary education will improve medical effectiveness of patient care. To construct a falls prevention framework for all healthcare workers, NST support for hospitals and healthcare workers, such as nurses and physical therapists, is necessary to develop appropriate education and training in relation to this type of patient care ${ }^{17}$. Falls were more frequent in physically restrained patients. Based on these results, we consider that, to reduce the incidence of falls and to prevent falls, it is necessary to determine the nutritional status and muscle mass of patients, using a falls assessment score sheet at the time of admission and through evaluating the nutritional status of patients from a biochemical perspective. Again, the environment of the hospital where patients spend their hospitalization is different from the home they were used to living in. Added to that change in environment is the decline in physical strength and motor functions due to illness or injury. Therefore, along with the medical staff, it is also an important multidisciplinary collaboration to keep close informed with the relatives (family) about how the patient is living at home. In this study, it is necessary to take into account the characteristics of each 
region and facility, so this is not a sufficient case study to provide information to readers as a general theory. Many falls result from interactions among multiple risk factors and the risk of falling increases linearly with the number of risk factors ${ }^{18}$. However, even among community-dwelling people aged 75 years and older without risk factors, approximately $10 \%$ fall during any given year ${ }^{19}$. Therefore, all older adults should be recognized as being at some increased risk of falling. However, many healthcare workers are continuously taking measures to prevent falls. Many facilities are taking measures to 1) reduce the factors that cause fall accidents, 2) monitor the mental and physical condition of patients, and 3) exercise to maintain physical functions ${ }^{20}$. It suggested that we should conduct patient physical assessments in cooperation with multiple professions on a daily basis and work with the PDCA cycle to ensure medical safety. Falls prevention is a challenge facing staff not only at the Chichibu Municipal Hospital but also staff at other municipal hospitals across Japan.

\section{CONCLUSIONS}

To reduce the occurrence of falls, it is necessary to consider the nutritional status and muscle mass of patients using a falls assessment score sheet at the time of admission. Additionally, we consider that some falls can be prevented through evaluating the nutritional status of patients from a biochemical perspective.

\section{Ethical consideration}

The study was approved by Josai University ethical committee in Saitama Japan (ninirin-2019-12A).

\section{Author contributions}

M.S. Y.I. and A.I. performed the experiments, participated in the study design, and carried out sampling and helped prepare the manuscript. T.O. and Y.K. participated in experiments, carried out sampling, and planned the study design, analyzed the experimental data, and contributed suggestions regarding the manuscript. All authors read and approved the final manuscript.

\section{FUNDING}

This research received no external funding.

\section{ACKNOWLEDGMENTS}

We would like to thank everyone who visited Chichibu Municipal Hospital for their cooperation in conducting this research. We would also like to thank all the hospital staff for their research support while taking measures against COVID-19 infection.

\section{CONFLICT OF INTEREST}

The Authors declare no conflict of interest.

\section{References}

1 United Nations. Department of Economic and Social Affairs Population: Dynamics, 2019 (https://population. un.org/wpp/Download/Metadata/Documentation/).

2 Tsuji I. Epidemiologic research on healthy life expectancy and proposal for its extension. A revised English version of Japanese in the Journal of the Japan Medical Association. JMAJ 2019;148:1781-1784. https://doi.org/10.31662/ jmaj.2020-0027

3 Imai H. What problems will we confront in 2025? An analysis of public health and welfare issues. J Natl Inst Public Health 2016;65:2-8.

4 Tsuda T. Epidemiology of fragility fractures and fall prevention in the elderly: a systematic review of the literature. Curr Orthop Pract 2017;28:580-585. https://doi.org/10.1097/ BC0.0000000000000563

5 Dhillon RJS, Hasni S. Pathogenesis and management of sarcopenia. Clin Geriatr Med 2017;33:17-26. https://doi. org/10.1016/j.cger.2016.08.002

6 Suzuki T. Geriatric syndrome: cause of long-term care. Rigakuryoho Kagaku 2003;18:183-186. https://doi. org/10.1589/rika.18.183

7 Chichibu City Official website. Chichibu - shi senior citizen welfare program - senior citizen welfare program and the $7^{\text {th }}$ period insurance of the elderly care business plan, 2018 (http:// www.city.chichibu.lg.jp/secure/1294/kaigokeikaku30.pdf).

8 Urakami K. Prevention of dementia. Nihon Rinsho 2016;74:395-398. In Japanese

9 Gutiérrez-Valencia M, Izquierdo M, Cesari M. The relationship between frailty and polypharmacy in older people: a systematic review. Br J Clin Pharmacol 2018;84:14321444. https://doi.org/10.1111/bcp.13590

10 Caughey GE, Roughead EE, Pratt N, et al. Increased risk of hip fracture in the elderly associated with prochlorperazine: is a prescribing cascade contributing? Pharmacoepidemiol Drug Saf 2010;19:977-982. https://doi.org/10.1002/pds.2009

11 Lee DR, Santo EC, Lo JC. Understanding functional and social risk characteristics of frail older adults: a cross-sectional survey study. BMC Fam Pract 2018;19:170. https:// doi.org/10.1186/s12875-018-0851-1

12 Correa-Pérez A, Delgado-Silveira E, Martín-Aragón S. Fallrisk increasing drugs and prevalence of polypharmacy in older patients discharged from an orthogeriatric unit after a hip fracture. Aging Clin Exp Res 2019;31:969-975. https:// doi.org/10.1007/s40520-018-1046-2

13 Ooi K. Evaluation of a pharmacist-led intervention on polypharmacy. Nihon Ronen Igakkai Zasshi 2019;56:498-503. In Japanese

14 Inoue Y, Sato T, Kanamoto I. The study of long-term nutritional management using semi-solid diet in hospitalized elder patients. Journal of Japanese Society for Medical Use of Functional Foods 2011;6:255-263. In Japanese

15 Walsh CM, Liang LJ, Grogan T. Temporal trends in fall rates with the implementation of a multifaceted fall prevention program: persistence pays off. Jt Comm J Qual Patient Saf 2018;44:75-83. https://doi.org/10.1016/j. jcjq.2017.08.009 
16 Oliveira JS, Sherrington C, Paul SS. A combined physical activity and fall prevention intervention improved mobilityrelated goal attainment but not physical activity in older adults: a randomised trial. J Physiother 2019;65:16-22. https://doi.org/10.1016/j.jphys.2018.11.005

17 Reeves S, Boet S, Zierler B. Interprofessional education and practice guide no. 3: evaluating interprofessional education. J Interprof Care 2015;29:305-312. https://doi.org/ 10.3109/13561820.2014.1003637
18 Phelan EA, Mahoney JE, Voit JC, et al. Assessment and management of fall risk in primary care settings. Med Clin North Am 2015;99:281-93. https://doi.org/10.1016/j. mcna.2014.11.004

19 Tinetti ME, Speechley M, Ginter SF. Risk factors for falls among elderly persons living in the community. $\mathrm{N}$ Engl $\mathrm{J}$ Med 1988;319:1701-1707.

20 Boyd R, Stevens JA. Falls and fear of falling: burden, beliefs and behaviours. Age Ageing 2009;38:423-428.

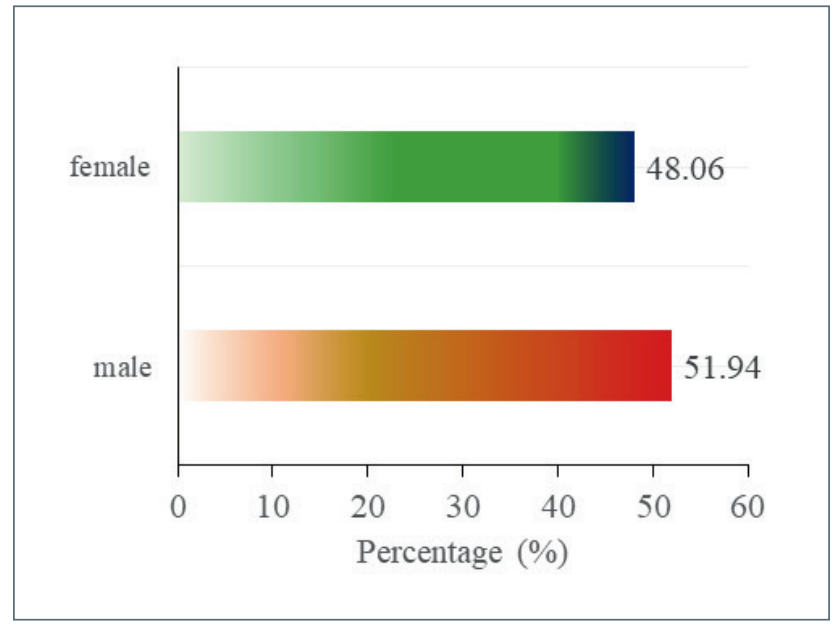

S.I 1. Patient classification according to sex.

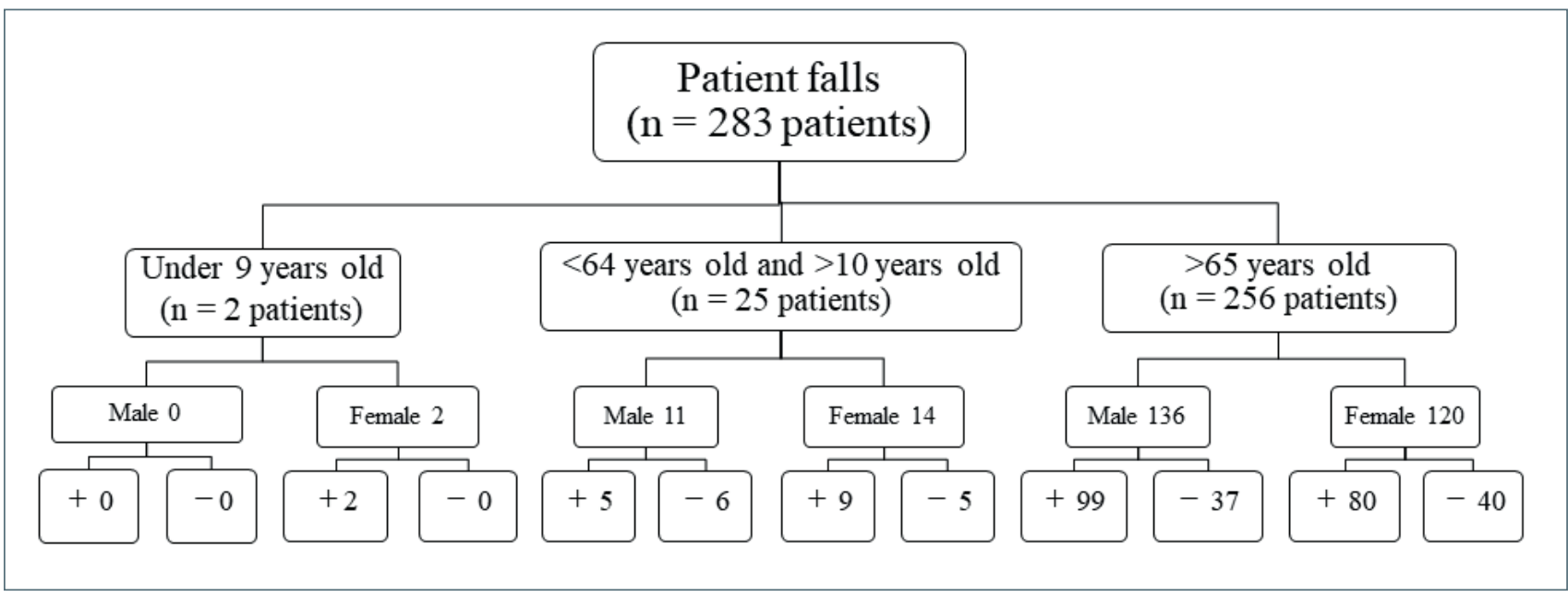

S.I 2. Patient age, sex, and medical history +, a positive medical history, -, a negative medical history 